\title{
Addressing the health-related SDGs in the Eastern Mediterranean Region: Regional Health Alliance strengthens collaboration towards better health
}

\begin{abstract}
Ahmed Al-Mandhari, ${ }^{1}$ Christoph Hamelmann, ${ }^{2}$ Arash Rashidian, ${ }^{3}$ Ruth Mabry, ${ }^{4}$ Ahmed Mandil, ${ }^{5}$ Jamal Nasher ${ }^{6}$ and Thamer Al Hilfi ${ }^{7}$
${ }^{1}$ Regional Director, World Health Organization Regional Office for the Eastern Mediterranean, Cairo, Egypt. ${ }^{2}$ Chef de Cabinet, World Health Organization Regional Office for the Eastern Mediterranean, Cairo, Egypt. ${ }^{3}$ Director, Department of Science, Information and Dissemination, World Health Organization Regional Office for the Eastern Mediterranean, Cairo, Egypt. ${ }^{4}$ Dr Ruth Mabry, International Public Health Expert. ${ }^{5}$ Coordinator, Research \& Innovation, Department of Science, Information and Dissemination, World Health Organization Regional Office for the Eastern Mediterranean, Cairo, Egypt. ${ }^{6}$ Coordinator, SDGs, Gender, Equity \& Human Rights, and RHA secretariat, Chef de Cabinet office, World Health Organization Regional Office for the Eastern Mediterranean, Cairo, Egypt. ${ }^{7}$ Technical Officer and RHA secretariat, Chef de Cabinet office, World Health Organization Regional Office for the Eastern Mediterranean, Cairo, Egypt.
\end{abstract}

Citation: Al-Mandhari A; Hamelmann C; Rashidian A; Mabry R; Mandil A; Nasher J; et al. Addressing the health-related SDGs in the Eastern Mediterranean region: Regional Health Alliance strengthens collaboration towards better health. East Mediterr Health J. 2022;28(1):3-4. https://doi.org/10.26719/2022.28.1.3

Copyright ( ) World Health Organization (WHO) 2022. Open Access. Some rights reserved. This work is available under the CC BY-NC-SA 3.0 IGO license (https://creativecommons.org/licenses/by-nc-sa/3.o/igo).

The United Nations launched the Sustainable Development Agenda 2030 and its 17 Sustainable Development Goals (SDGs) in 2015, as a more detailed and ambitious follow-up to the Millennium Developments Goals (MDGs). Health and wellbeing of all, at all ages, is addressed by the third SDG (SDG3) and health-related targets of other SDGs. However, progress to date on the health-related SDGs in the Eastern Mediterranean Region (EMR) is not on track (1). Although there was progress in over half of the 50 health-related SDG targets and indicators between 2015 and 2019, there is still a long way to go. Progress is required, among others, in reducing maternal, child and neonatal mortality; increasing vaccination coverage; reducing the number of cases of malaria and HIV; and in tackling the increase in mortality rates due to noncommunicable diseases (2). Much progress is needed in many health-related SDGs considered as important social, economic and environmental determinants of health.

The regional Vision 2023, Health for All by All (3), launched in 2019 by the WHO Regional Office for the Eastern Mediterranean (WHO EMRO) and its accompanying strategy (4) contextualizing the WHO 13th Global Programme of Work for the region is anchored and contributes to achieving the Sustainable Development Agenda 2030 SDGs. In 2019, WHO, with 11 multilateral health and development partners, launched the Global Action Plan for Healthy Lives and Well-being for All to help accelerate progress towards health-related SDGs (5).

In 2020, the Regional Health Alliance, a key priority partnership of Vision 2023, was launched to harmonize action between regional partners and foster new ways of working to accelerate progress on the health-related SDGs and implement the Global Action Plan in the Region. Hosted by WHO EMRO, the Alliance comprises the regional offices of UNAIDS, UNDP, UNFPA, UNICEF, UN Women, the World Bank Group, and WFP, which are all signatories to the Global Action Plan for Healthy Lives and Well-being for All, as well as IOM, UNESCO, UNHCR and ITU. The Alliance's Joint Action Plan 2020-2021 developed in mid-2020 and implemented by working groups linked to the seven accelerators (i.e. primary health care; sustainable financing for health; community and civil society engagement; health determinants; innovative programming in fragile and vulnerable settings; research and development, innovation and access; data and digital health) plus a gender advisory group to enhance collaboration toward the shared objectives. This regional platform represents a new innovative approach to partnership for achieving health impact at country level (6).

In its second annual meeting on 16 December 2021, the Alliance welcomed three more agencies to the partnership: UN-Habitat, UNIDO and UNOCHA. In that meeting, which marked the first anniversary of the Alliance, progress was reviewed, gaps and challenges were identified, and success stories and lessons learned shared across the four commitments of: engage, accelerate, align, and account (7). The meeting was used to highlight some key successes in joint action. These include successful completion of online training on primary care and COVID-19 for 100000 physicians in the region, four region-wide publications on financing for health, mapping of training needs for community health workers, health innovations for COVID-19 response, and the development of national digital health strategies in some countries of the EMR. The United Nations collaborative action went beyond the joint plan such as rolling out COVID-19 vaccinations to refugees and migrants, engaging youth to visualize SDGs, and developing the Social, Economic, and Environmental Design (SEED) Identifier tool (8), to enable policymakers to understand and address inequities and the impact of social, economic and environmental development on health. Despite these and many more promising progress stories, it was noted that further consolidated action from the Alliance members as well as countries of the region is required; otherwise achieving several health- 
related SDGs may remain a remote possibility for several countries (1).

During the closing session of the December 2021 meeting, the Regional Health Alliance Joint Action Plan 2022-2023 was launched. The Plan builds on achievements during 2020-2021 and aims at stepping up work on improving access to quality health services for all, enhancing community engagement, improving financial protection, protecting healthy environments, promoting new health products, and fostering health information systems. This biennial plan aims for stronger United Nations collaborative action on the health-related SDGs by supporting countries in tackling the underlying social determinants of health, scaling-up key health technologies, and advocating health and development and peace as a coherent nexus in emergency countries.

This strategic partnership is all about collaborative action for country impact. Thus, planned activities aim to reinforce the efforts of United Nations country and regional teams, guided by the United Nations Sustainable Development Cooperation Framework (UNSDCF).
Emphasis on country level and country focused action is crucial since half of the region's population are facing long-term conflicts, environmental threats and natural disasters alongside the COVID-19 pandemic (9). This is consistent with a recent review that recommends scalingup actions to strengthen partnerships and build strategic alliances to drive public health impact in the countries of the region (10).

In conclusion, the Regional Health Alliance brings together 15 health and development partners to improve health in the region and progress on health-related SDGs. The Alliance is a partnership that implements the WHO's vision for the Region to achieve "Health for All by All". The initial joint activities demonstrated the added value of a regional alliance, which can be exemplary and provide best practice under the United Nations Regional Collaborative Platform towards accelerating progress toward health-related SDGs. Strengthening agency alignment will enable partner agencies to confront the Region's challenges and improve coordination efforts to maximize impact in countries and promote health and wellbeing of its populations.

\section{References}

1. World Health Organization. Progress on the Health-related Sustainable Development Goals and targets in the Eastern Mediterranean Region 2020. Cairo: WHO Regional Office for the Eastern Mediterranean, 2021, http://www.emro.who.int/images/stories/ est/documents/progress-on-health-related-sdgs-and-targets.pdf?ua=1.

2. Doctor HV; Mabry R; Kabudula CW; Rashidian A; Hajjeh R; Hussain SJ; et al. Progress on the health-related Sustainable Development Goals in Eastern Mediterranean Region countries: getting back on track in the time of COVID-19. East Mediterr Health J. 2021;27(6):530-534. https://doi.org/10.26719/2021.27.6.530.

3. World Health Organization. Vision 2023 Eastern Mediterranean Region: Health for All, by All. Cairo: WHO Regional Office for the Eastern Mediterranean, 2019, https://applications.emro.who.int/docs/RD_Vision_2018_20675_en.pdf?ua=1\&ua=1.

4. World Health Organization. WHO's strategy for the Eastern Mediterranean Region, 2020-2023. Turning Vision 2023 into action. Cairo: WHO Regional Office for the Eastern Mediterranean, 2021, https://applications.emro.who.int/docs/EMRPUB-RDO-0142019-EN.pdf?ua=1.

5. World Health Organization. Stronger Collaboration Better Health, Global Action Plan on Healthy Lives and Well-being for All, 2019, https://apps.who.int/iris/rest/bitstreams/1250381/retrieve.

6. World Health Organization. The WHO Transformation: 2020 progress report. Geneva: World Health Organization, 2020, https:// www.who.int/publications/i/item/9789240026667.

7. World Health Organization. The Global Action Plan for Healthy Lives and Well-being for All (SDG3 GAP), Monitoring Framework, May 2021, https://www.who.int/publications/i/item/9789240026209.

8. SEED Network. SEED Evaluator 3.o Instructional Overview, June 2015, https://seednetwork.org/wp-content/uploads/2015/07/ English-Evaluator-Instructions.pdf.

9. Al-Mandhari A. Rebuilding better and fairer in the Eastern Mediterranean Region - the 68th session of the WHO Regional Committee. East Mediterr Health J. 2021 Oct 27;27(10):945-946. https://doi.org/10.26719/2021.27.10.945.

10. World Health Organization. Vision 2023: health for all by all in the Eastern Mediterranean Region: Midterm Push Forward Plan - an overview. Cairo: World Health Organization, 2021, https://applications.emro.who.int/docs/RC68-SM8-eng.pdf. 